\title{
SENSITIVITY ANALYSIS OF INPUT PARAMETERS FOR LOAD CARRYING CAPACITY OF MASONRY ARCH BRIDGES
}

\author{
Marek VoKáL*, Michal Drahorád \\ Czech Technical University in Prague, Faculty of Civil Engineering, Department of Concrete and Masonry \\ Structures, Thakurova 7/2077, 16629 Prague 6 Dejvice, Czech Republic \\ * corresponding author: marek.vokal@fsv.cvut.cz
}

\begin{abstract}
The article deals with an analysis of railway masonry arch bridges. Typical attributes of these bridges are pointing loss and backfill. Therefore, the material - masonry - behaviour can be described only by a non-linear stress-strain diagram, mainly because of low or no tensile strength. The load carrying capacity, which is one of the main parameters when assessing the bridge, is a non-linear problem with many inputs, such as properties of backfill and masonry, backfill depth and geometry of the arch. Some of these parameters can be obtained by a diagnostic survey or from archival documentation. Some of these parameters impact the calculation greatly and some negligibly. The identification of key parameters, which must be stated by the diagnostic survey, is the goal of this article.
\end{abstract}

KEYWORDS: Non-linearity, masonry, arch bridge, load carrying capacity.

\section{InTRODUCTION}

In the Czech Republic, masonry vault bridges account for $35 \%$ of railway bridges. A similar portion of masonry bridges can be found throughout the whole Europe. According to [1], $80 \%$ of Czech masonry vault railway bridges are older than 100 years. $85 \%$ of Czech masonry vault railway bridges are in a "good" structural state, $14 \%$ are in a "bad" structural state and $1 \%$ are in a serious, unsatisfactory structural state.

This is due to the lack of bridge maintenance and the uncertainty of the inspectors in the assessment. The consequence of such a structural state is a low load carrying capacity (hereinafter referred as "LCC"), which is given by the bridge inspection by multiplying the original LCC by $\alpha_{s}$, which is $\leq 1$. Consequently, the bridge manager chooses to replace the vault with another bridge. However, the real load capacity determined by a calculation is often significantly higher. The various methods of calculating the LCC and the influence of individual input calculation parameters on the resulting load capacity is being discussed in this article.

The methods used for assessing masonry arch bridges are described in [2], for the purpose of this article, the methods can be divided into:

- Historical simple methods such as a graphical method.

- Methods used for a real-time praxis, which tend to be as precise as possible.

- Scientific methods, which might be used mainly for theoretical purposes.

An example of a scientific method is a fracture model used by the software ATENA, which is described, for example, in [3], the parameter "Specific fracture energy" $G_{f}$ is an important input parameter ("higher values of fracture energy considerably increases both the limit displacement and the loadbearing capacity"). Despite this fact, parameter $G_{f}$ is practically impossible to get. Therefore, this article uses real-time methods and describes how to use them in a praxis by showing some examples. The sensitivity analysis shows the importance of the input parameters.

\section{Methodology AND METhods}

\subsection{Methodology of analysing LCC}

The LCC is described by moving load, which can be safely carried by the bridge. Conditions, which must be fulfilled, are specified by current codes - Eurocodes, namely by 4 . Eurocodes define Serviceability limit state - SLS (which provides the usability and durability of the structure) and Ultimate limit state - ULS (the state of collapse of the structure, also ensures the durability of the structure in general). The LCC of railway bridges is based on load model 71 [5], which is also used for the design of new railway bridges. (It consists of forces $4 \times 250 \mathrm{kN}$ and a uniform continuous distributed load of $80 \mathrm{kN} / \mathrm{m}$.) The LCC (in plots named $Z_{L M 71}$ according to [6]) is equal to a multiple of load model 71 , which can pass the bridge while fulfilling the conditions of the ULS and SLS. The LCC of new bridges must be at least 1 .

Nine masonry vault railway bridges of a circular shape were analysed in this article (for specification see 2.2.1 using the program LimitState:RING [7]. Then, the LCC was analysed for the road bridge span 4 of the Legion Bridge in Prague, which has an elliptic shape and span 5 , which has a circular shape. This bridge was loaded by the railway load model 71 in order to compare the result with other bridges studied 
in this article. A finite element program Midas [8] was used for modelling, which allowed us to also model temperature load. As a source for this calculation, the real diagnostic survey is available - see [9]. This survey is very detailed and was quite expensive. This article was created to help to save some money for the diagnostic surveys and to focus only on the most important parameters.

In all these models, average input parameters were used and then, one parameter was considered variable and its impact on the final LCC was examined. The resulting $\mathrm{LCC}$, in dependence of this parameter, was plotted in a separate graph. The goal of this article is to determine which parameters impact the resulting LCC the most.

\subsection{Assumptions of ANALYSis, USED METHODS}

Two programs, which use a special method of modelling, were used:

\subsubsection{LimitState:RING}

This program is designed for a collapse analysis Ultimate limit state. Cracks can open up, parts of a cross section can crush. See the details of crushing in the section 3.2 .

In the program LimitState:RING, the masonry vault is modelled as a system of rigid blocks. The method is based on computational limit analysis methods (also known as "plastic" or "mechanism" methods). If the lines of thrust lie entirely within the masonry cross section and also the hinges form at the locations, where the lines of the thrust touch maximally the exterior faces of the blocks, the structure doesn't collapse. If the thrust lines lie out the cross section, a hinge is created. Formation of a sufficient number of hinges (and / or planes of sliding) leads to a collapse.

A calculation is carried out in the following steps: a calculation of internal forces on a linear beam model; finding the points of vault, where the collapse of masonry block occurs; finding the collapse mechanism; build up equation (equilibrium of blocks) with the unknown of safety factor - the multiple of traffic loads, which cause the collapse. These equations are built up on theory of rigid bodies, where the vault is divided by the collapsed block. Number of such a collapsed block has to be as big as to create a moveable mechanism.

The resulting collapse mechanisms can be divided into the following cases:

- Mode I - collapse by crush of masonry - see Figure 1 .

- Mode II - Collapse by opening of cracks - see Figure 2

- Mode III - Collapse by shear between the blocks see Figure 3

LimitState:RING was used for nine vault circular bridges. The spans chosen were 6,12 and $20 \mathrm{~m}$, ratios of $v / L$ (sagitta/span length) chosen were $0.1,0.3$ and 0.5. In the legend of the plot, "06_0.6" means span

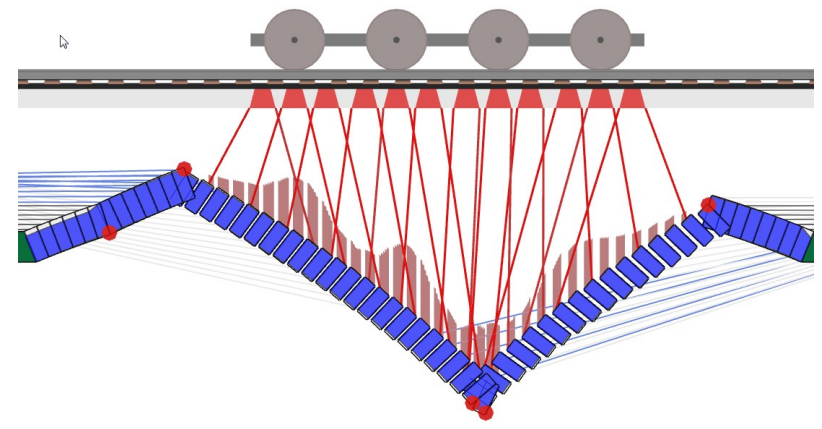

Figure 1. Collapse by crush of masonry (mode I).

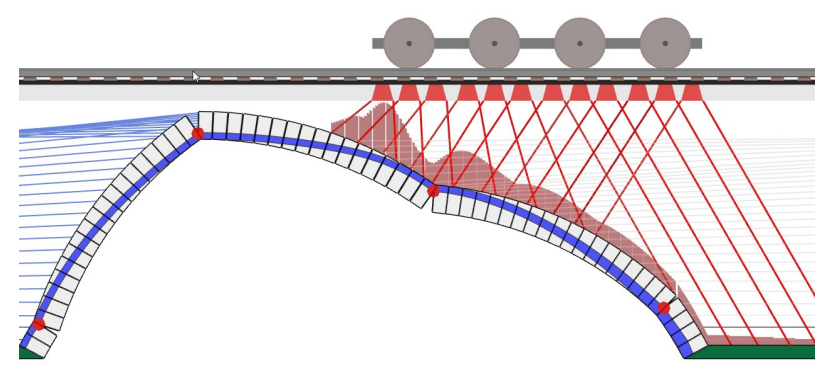

FIGURE 2. Collapse by opening of cracks (mode II).

$6 \mathrm{~m}$, sagitta $0.6 \mathrm{~m}$, which means ratio 0.1 . The ratio $p / L$ (depth of backfill at the top of the arch/span length) is 0.08333 . The total depth of the backfill is, therefore, $0.5 \mathrm{~m}$ for the span of $6 \mathrm{~m}, 1 \mathrm{~m}$ for the span of $12 \mathrm{~m}$ and $1.666 \mathrm{~m}$ for the span of $20 \mathrm{~m}$. The default value of the specific weight of masonry is $25 \mathrm{kN} / \mathrm{m}^{3}$, is $18 \mathrm{kN} / \mathrm{m}^{3}$ of backfill, compressive strength is $5 \mathrm{MPa}$, friction coefficient 0.6 , angle of internal friction of soil $30^{\circ}$, cohesion of soil is considered zero. The thickness of the vault is considered $0.4 \mathrm{~m}$ for the span of $6 \mathrm{~m}$, $0.5 \mathrm{~m}$ for the span of $12 \mathrm{~m}$ and $0.6 \mathrm{~m}$ for the span of $20 \mathrm{~m}$. The temperature cannot be handled in this program.

\subsubsection{MIDAS}

Midas is a typical FEM software. Its basic assumption is "small" deformation, see the definition in [10] and [11. For masonry structures, a small deformation assumption is fullfilled. It is, therefore, used for a verification of a structure in an elastic state - in Serviceability limit state. For the modelling of the Legion Bridge, elastic plate elements were used. The material non-linearity is modelled only in the joints between masonry blocks. The model was proposed in [12, see the details about this model in [13]. There are around 20 elastic links in every joint representing the mortar, which can resist shear and compressive forces only (tension prevented). The calculation is carried out iteratively. The load is being increased until the capacity of at least one of the cross sections according to equation 2 or (and) 3 is exhausted.

The parameters of this model according to [9]: Young's modulus of elasticity of masonry is $27.085 \mathrm{GPa}$, the span 4 is $42.5 \mathrm{~m}$, the thickness of the arch is ranging from $1.45 \mathrm{~m}$ to $2.1 \mathrm{~m}$, the span 5 is 


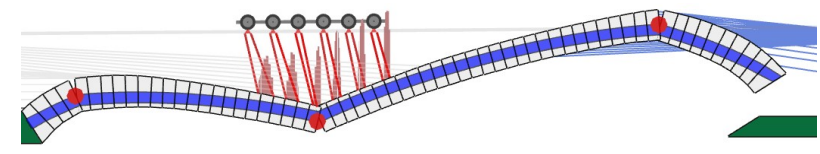

Figure 3. Collapse by shear between the blocks (mode III).

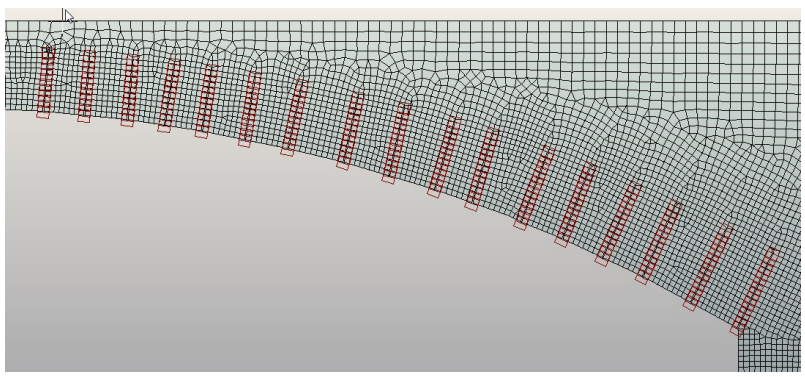

Figure 4. Model of Legion Bridge (right half of fifth span).

$27.9 \mathrm{~m}$, the thickness of the arch is changing from $1.0 \mathrm{~m}$ to $1.5 \mathrm{~m}$. The specific weight of masonry is considered $26.44 \mathrm{kN} / \mathrm{m}^{3}$ (granite stone blocks), specific weight of soil $19.5 \mathrm{kN} / \mathrm{m}^{3}$, coefficient of thermal expansion 4.5e-06 ${ }^{\circ} \mathrm{C}^{-1}$, see Figure 7 in section 3.1 .

\subsection{INVESTIGATED PARAMETERS}

- Midas.
(1.) Uniform change of temperature.
(2.) Coefficient of thermal expansion.
(3.) Modulus of elasticity.

- LimitState:RING.

(1.) Masonry strength.

(2.) Coefficient of friction in joints of masonry.

(3.) Backfill depth.

(4.) Backfill slope.

(5.) Specific weight of masonry.

(6.) Specific weight of backfill.

(7.) Backfill angle of internal friction.

(8.) Backfill cohesion.

(9.) Effective vault width.

(10.) Poisson number.

(11.) Shape of vault.

(12.) Vault thickness.

\section{Results of the MOdELling}

\subsection{Temperature Changes, COEFficient OF THERMAL EXPANSION, MODULUS OF ELASTICITY}

This section presents the results of the modelling of the Legion Bridge in the program Midas. The final plot of the LCC is based on the input parameters from the diagnostic survey.

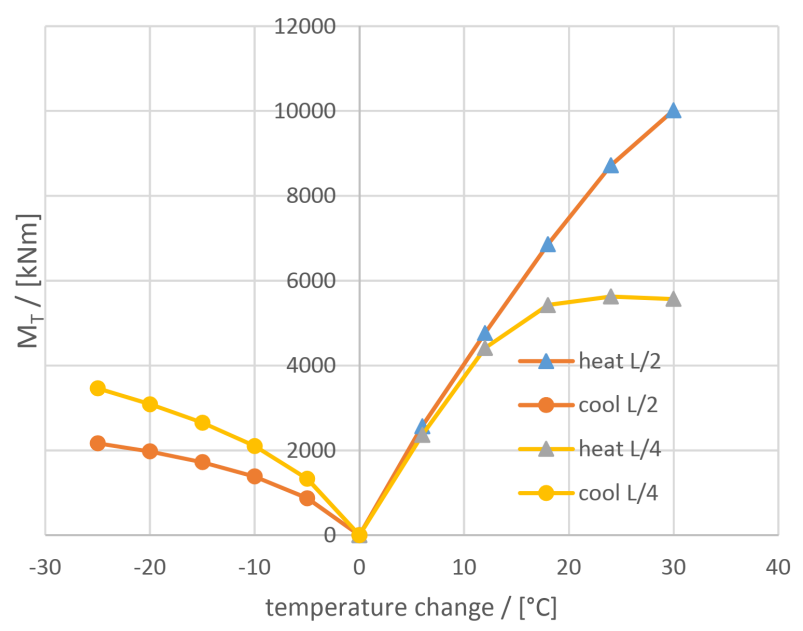

Figure 5. Bending moment of span 4 due to the uniform change of temperature (absolute values).

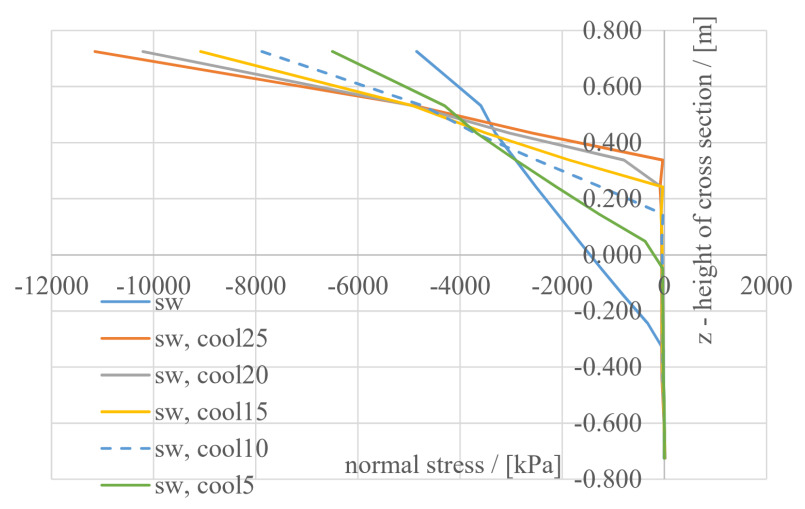

Figure 6. Normal stresses in the middle of span 4.

Bending moments due to uniform temperature changes - increasing $(+)$ and decreasing (-) of superstructure temperature can be seen in the Figure 5

Bending moments were obtained by an integration of normal stresses over the cross-section in the points of the structure with the highest value of bending moments $-L / 2$ and $L / 4$, where $L$ is the length of the span. The resulting bending moment was obtained by subtracting the moment caused by the dead load from a combination of dead load and change of temperature. An example of the stress distribution in the cross section is shown in the Figure 6 .

In analogy to both-end-fixed beam subjected to uniform temperature gradient, where:

$$
\sigma=E \cdot \alpha_{t} \cdot \Delta t
$$

$E$ - Young's modulus of elasticity, $\alpha_{t}$ - coefficient of thermal expansion, $\Delta t$ - change of temperature. As $\varepsilon$ and $\sigma$ depends on $E, \alpha_{t}$ and $\Delta t$, because $\varepsilon=\alpha_{t} \cdot \Delta t$ and $\sigma=E \cdot \varepsilon$, a more detailed analysis is provided for the investigation of the effect of the temperature change. The resulting stress arises from a multiplication of three parameters, afterwards we will focus on them together. All the three parameters can be con- 


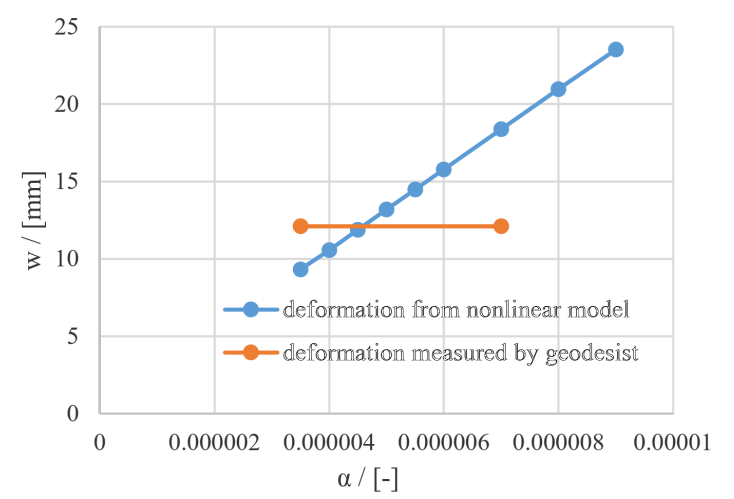

FiguRE 7. Finding out the $\alpha_{t}$ from a geodetic survey.

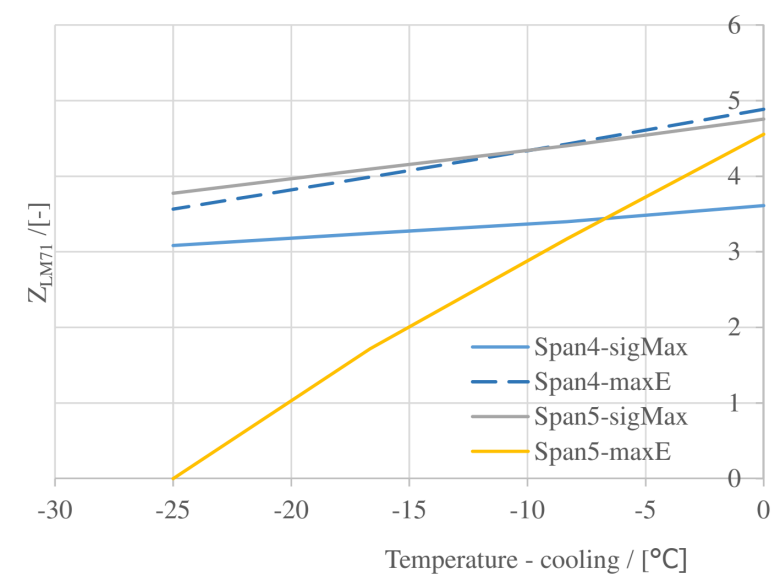

FiguRE 8. Load carrying capacity in dependence on temperature.

sidered as parameters of linear function - if Young's modulus considered in the calculation decreases twice, the resulting stress also decreases twice. The fact that this rule can be applied for masonry arch bridges, is proven by the Figure 7. In Midas model, the coefficient $\alpha_{t}$ was changed while the $\Delta t$ and $E$ is considered constant (this is known from the diagnostic survey). A linear function of deformation in dependence on the coefficient of the thermal expansion was obtained.

In the Figure 7, $w$ is a vertical deformation in the middle of the span 4. In the case of the Legion Bridge, the geodetic survey was done several times, $w$ was measured and the temperature of the structure was known, so the coefficient of thermal expansion could be obtained from the intersection point of a linear function and constant $w$ (the resulting $\alpha$ equals $\left.4.5 \mathrm{e}-06{ }^{\circ} \mathrm{C}^{-1}\right)$.

Resulting LCC can be seen in the Figure 8 .

Positive temperature change of the structure is not considered, because it does not have an adverse effect on the load carrying capacity according to SLS.

In the legend of Figure 8 sigMax and maxE denote two conditions to be fulfilled in SLS according to [6]:

(1.) Maximal stress ( $\operatorname{sigMax}$.

$$
\sigma_{n, \max }=\frac{N_{E k}}{3 b(h-2 e)} \leq 0.45 f_{k} .
$$

(2.) Maximal eccentricity (maxE).

$$
h_{c} \geq \frac{h}{2} \longrightarrow e \leq \frac{h}{3},
$$

where: $M_{E k}$, is the characteristic bending moment due to load, $N_{E k}$ is the characteristic normal force due to load. $e=M_{E k} / N_{E k}$. $h_{c}$ is the height of compressed area, $h$ is the height of cross section, $b$ is the width of cross section, $f_{k}$ is the characteristic strength of masonry.

From the Figure 8, it can be seen, that the circular shape of the vault is more sensitive to the cooling.

\subsection{MASONRY STRENGTH}

The following formula for the characteristic compressive strength of the masonry in an accordance with Eurocodes is used:

$$
f_{k}=K f_{b}^{\alpha_{m}} f_{m}^{\beta},
$$

where: $K$ is the coefficient depending on the masonry type and elements, $\alpha_{m}$ is the coefficient depending on the type of joints and the mortar, $\beta$ is the coefficient depending on the mortar type and composition, $f_{b}$ is the average normalized compressive strength of masonry units, $f_{m}$ is the average compressive strength of the mortar.

The determination of masonry strength is very sensitive to both the strength of masonry units and strength of mortar. One can directly see, that the power of 0.7 is higher than 0.3 , and therefore the parameter of masonry units is more sensitive. However, the values of the strength of the mortar usually have much larger variance.

For the example of Legion bridge, the mortar strength varies from $3.5-20 \mathrm{MPa}$ in 59 tests, the coefficient of variation equals $54 \%$, the masonry unit strength varies from $100-164 \mathrm{MPa}$ in 20 tests, the coefficient of variation equals $16 \%$.

The resulting parameters of assessing the $f_{k}$ are: $\alpha_{m}=0.7$ for usual mortar, $\beta=0.3$ for usual mortar, $K=0.45$ for blocks of natural stone, $f_{b}=76.7 \mathrm{MPa}$ (mean value), $f_{m}=17 \mathrm{MPa}$ (mean value). The final characteristic compressive strength of the masonry was calculated as $28.9 \mathrm{MPa}$ (which is very high value). See the details of the assessment of the masonry unit strength in 14. The design strength of masonry is calculated from characteristic strength by dividing it by $\gamma_{M}$, the partial factor for material properties (usually approximately equals 2).

The program LimitState:RING gives two options for the analysis. The compressive force in the vault is transferred by the joints:

(1.) Through an infinitely thin strip of stone at the edge of the vault (external when collapsing towards 


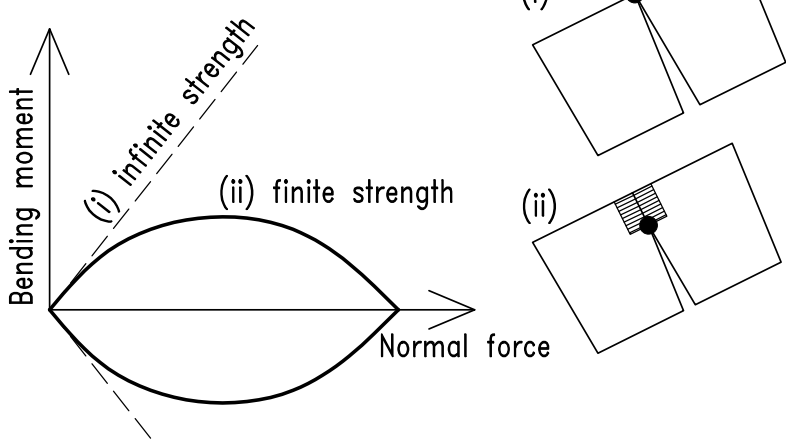

Figure 9. M-N diagram, compressed area.

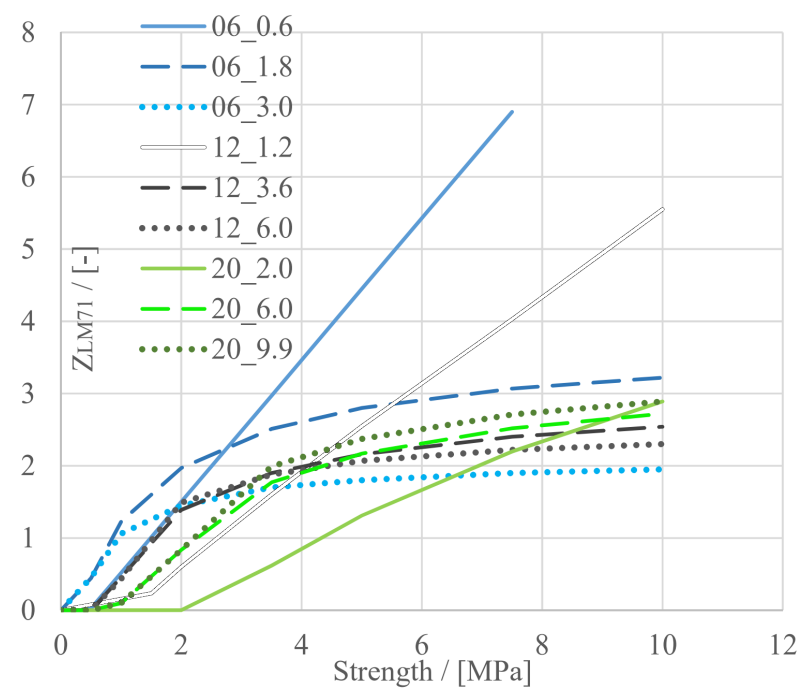

FiguRE 10. Load carrying capacity in dependence on design strength of masonry. For the legend see section 2.2 .1

the inside of the arch, internal when deflecting outside the arch), if infinite strength of the masonry is assumed.

(2.) Through a rectangular strip that represents the stress at which the masonry is crushed.

It is possible to plot a graph of the dependence of the moment of resistance on the given normal force for both options9. In the case of infinite strength (i) the task is linear, in the case of finite strength (ii) - considering crushing - the task is non-linear. The program solves the non-linear crushing problem as an iterative linear problem with defined boundary conditions under which a sufficient calculation precision is fulfilled. In this article, crushing of masonry is considered.

See the results obtained from modelling in program LimitState:RING in the Figure 10 .

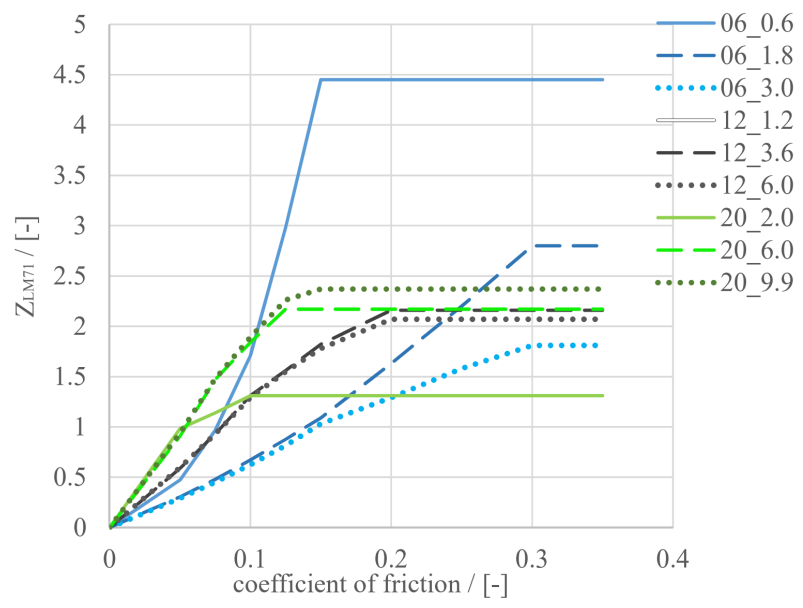

FIGURE 11. Load carrying capacity governed by shear in dependence on coefficient of friction.

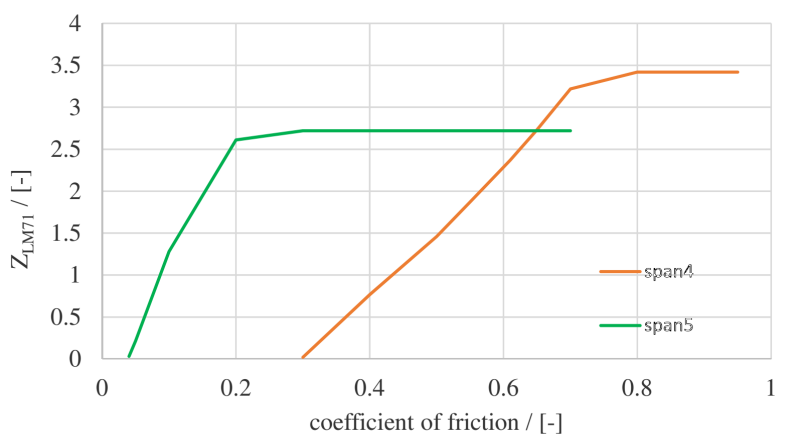

FIGURE 12. Load carrying capacity in dependence on the coefficient of friction - Legion Bridge, span 4.

\subsection{Coefficient of Friction in JOINTS OF MASONRY}

The collapse mode III (shear mode) might occur if the shear resistance is not satisfactory. The shear is checked in the ultimate limit state only. Shear resistance is determined as:

$$
V_{R d}=\left(f_{v k 0}+\mu \sigma_{d}\right) b\left(h-2 e_{u}\right) / \gamma_{M},
$$

where: $f_{v k 0}$ - characteristic shear strength of masonry, $\mu$ - coefficient of friction, $\sigma_{d}$ - normal stress from the design forces, $e_{u}=M_{E d} / N_{E d}$. Normal stress has the most significant influence on the shear resistance multiplied by the coefficient of friction $\mu$. The normal force arises from the shape of the vault and load applied. Figure 11] shows the LCC of nine circular bridges depending on the coefficient of friction. The LCC, according to the shear, is quite high.

Figure 12 displays the LCC of the Legion Bridge, which is significantly lower. Differences are due to the shape of the arch. For a circular arch shape, the collapse occurs if the value of $\mu$ is 0 , for the Legion Bridge, the collapse occurs if the value of $\mu$ is 0.3 for the span 4 and 0.03 for the span 5 .

It is obvious that the LCC for shear depends strongly on the shape of the arch, the LCC of a part-ofellipse is much lower because of the shear. In general, 


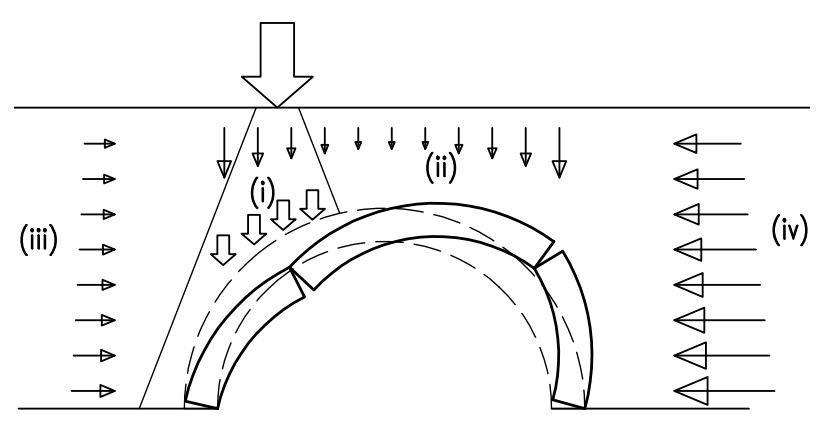

Figure 13. Impacts of backfill on the vault (i disperse of live load, ii - self weight of the soil, iii active earth pressure, iv - passive earth pressure.

this is a common problem of ellipse vault bridges. Therefore, it is necessary to consider the combination of shear forces from a transport load with shear forces from a temperature change (increasing of the temperature of structure is decreasing the LCC). For the sensitivity analysis of vaults of different shapes see chapter 3.12 From the Figure 12, it can also be seen, that for each vault exists a value of coefficient of friction, which, when increasing, does not cause an increase of the LCC, because the collapse mode III doesn't occur any more. According to [15], the coefficient of friction has the value from 0.597 to 0.705. According to the LimitState:RING manual, the coefficient value is 0.6 . According to the current standards - 4], the coefficient of friction $\mu$ is 0.4 and should be divided by a coefficient $\gamma_{M}$, which is usually equal to 2 . Therefore, the coefficient of friction is equal to 0.2 for new structures. For the Legion Bridge, the LCC is around zero, according to Figure 12 . However, this is not true, the real coefficient of friction is much higher. Current standards do not specify the value of the coefficient of friction for existing bridges.

\subsection{DePth OF BACKFILL}

The Figure 13 was taken from [16]. The depth of the backfill impacts the final LCC in several ways.

For the vaults of low sagitta (rise of arch), the LCC decreases when the depth of the backfill is increasing, because the compression, which is decisive, is growing. For other vaults, the LCC is growing, because the vault is stabilized, see the Figure 14 .

Due to the fact that the backfill influences the final LCC in many ways, further investigation of some parameters of the backfill is provided.

\subsection{BACKFILL SLOPE}

Obviously, the longitudinal slope of the railway or road causes an asymmetrical load of the vault. For ease of construction and taking into account the fact that the longitudinal slope on the bridge can be changed during the reconstruction, the vault shape has not been usually changed. Therefore, the longitudinal slope is a factor that always reduces the final LCC of the bridge, see the Figure 15.

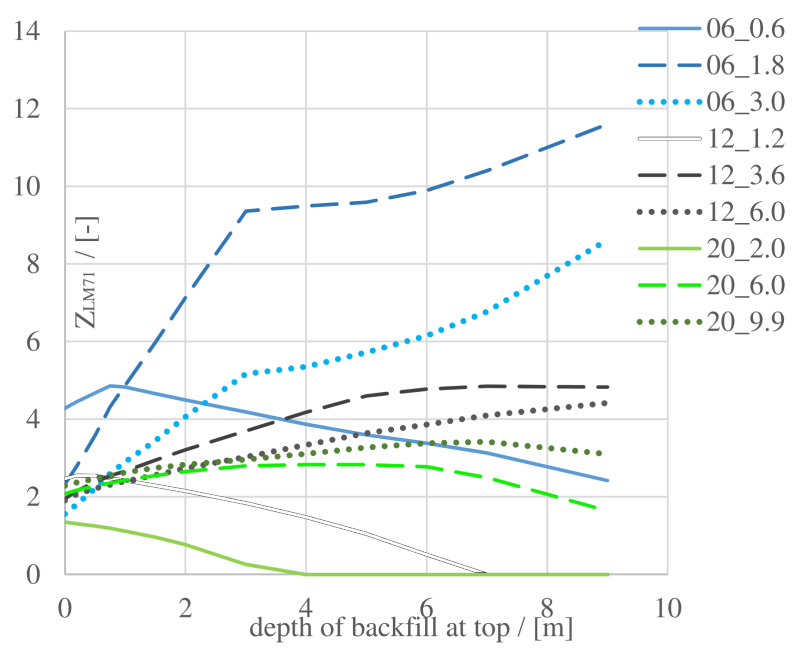

FIGURE 14. Load carrying capacity in dependence on the depth of backfill.

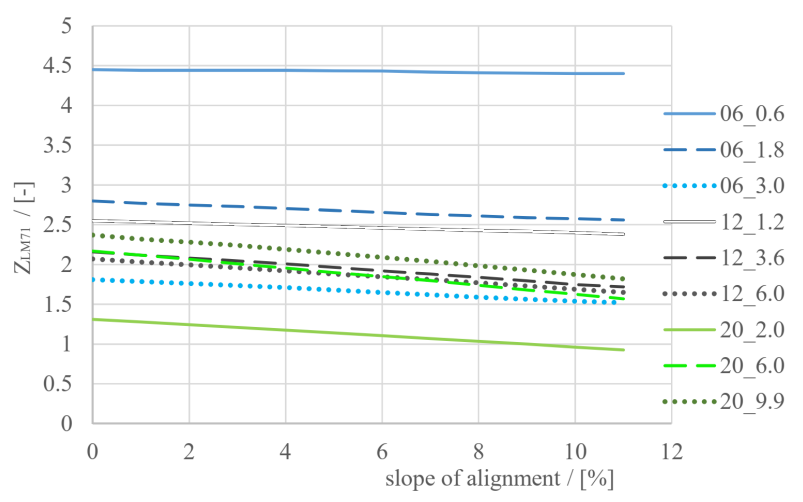

Figure 15. Load carrying capacity in dependence on longitudinal slope.

\subsection{SPECIFIC WEIGHT OF MASONRY}

Increasing the symmetry of the load is positive for the overall stability of the vault, as the effect of unsymmetric loads (e.g. traffic load) is reduced. Therefore, it usually increases the final LCC. The calculation assumed finite compressive strength, a value of $5 \mathrm{MPa}$ was considered. For the arch, with low sagitta (solid line in the plot), the increase of specific weight causes that stresses exceed the compressive strength and crushing failure mode occurs, which decreases the final LCC, see the Figure 16 .

\subsection{BULK DENSITY OF THE BACKFILL}

The effect of bulk density of the backfill is similar to the effect of specific weight of masonry. Within the range of relevant specific weight, which can occur, we can say that the masonry specific weight parameter is less sensitive than the parameter of bulk density of the backfill, see the Figure 17

\subsection{ANGLE OF INTERNAL FRICTION OF SOIL}

Horizontal stress, which acts on the extrados (if the direction of deformation is towards the soil - see the 


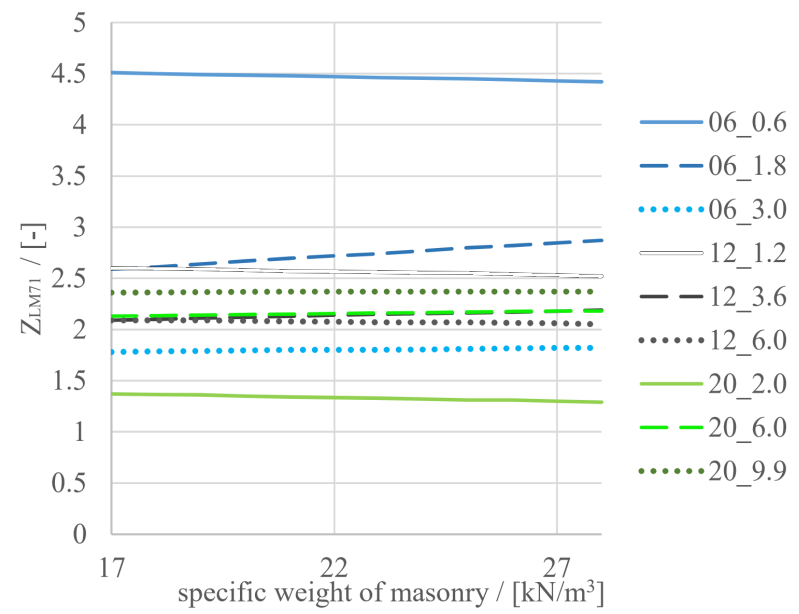

Figure 16. Load carrying capacity in dependence on specific weight of masonry.

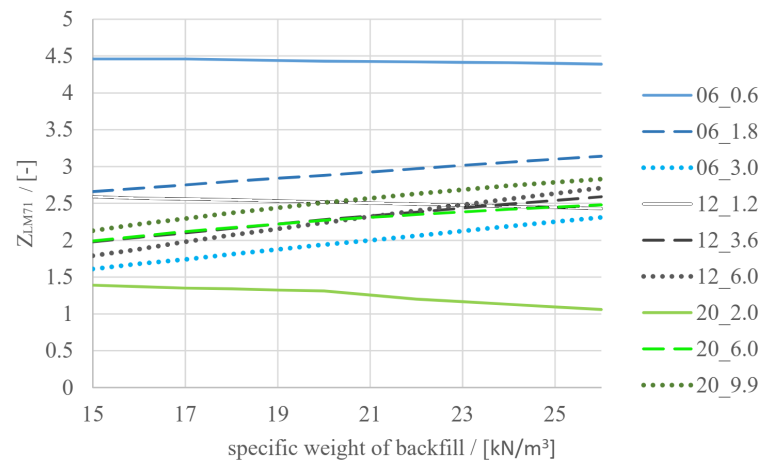

FiguRE 17. Load carrying capacity in dependence on specific weight of backfill.

blue lines in the Figure 2 is calculated according to [7] as:

$$
\sigma_{h}=m_{p} \cdot K_{p} \cdot \sigma_{v}+m_{p c} \cdot K_{p c} . c
$$

where

$$
\begin{gathered}
K_{p}=\frac{1+\sin \varphi}{1-\sin \varphi}=\tan ^{2}\left(45^{\circ}+\varphi / 2\right), \\
K_{p c}=2 \sqrt{K_{p}},
\end{gathered}
$$

$m_{p}=0.33$ - coefficient obtained experimentally, $\sigma_{V}$ is the vertical earth pressure due to dead loads, $m_{p c}=$ 0.05 - coefficient obtained experimentally, $c$ is cohesion of the soil.

Values of $m_{p}$ and $m_{p c}$ (see [7]) has been shown to give a reasonable prediction of the collapse load in physical model tests on single span bridges. By default settings of the program and according to [7], which arises from experiments, the value of $m_{p} . K_{p}$ is greater than or equal to 1 , which means, that $\varphi \geq 30$. From these assumptions, we get a following plot - Figure 18 .

If we consider that $m_{p} . K_{p}$ can be lower than 1 , we get the plot - Figure 19 .

As it can be seen from the Figure 19, the increase of the angle of internal friction increases the final

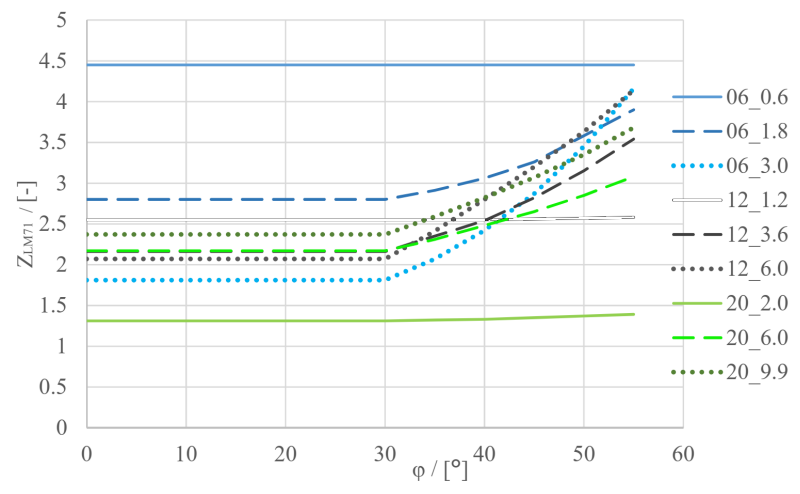

FIGURE 18. Load carrying capacity in dependence on angle of internal friction of soil.

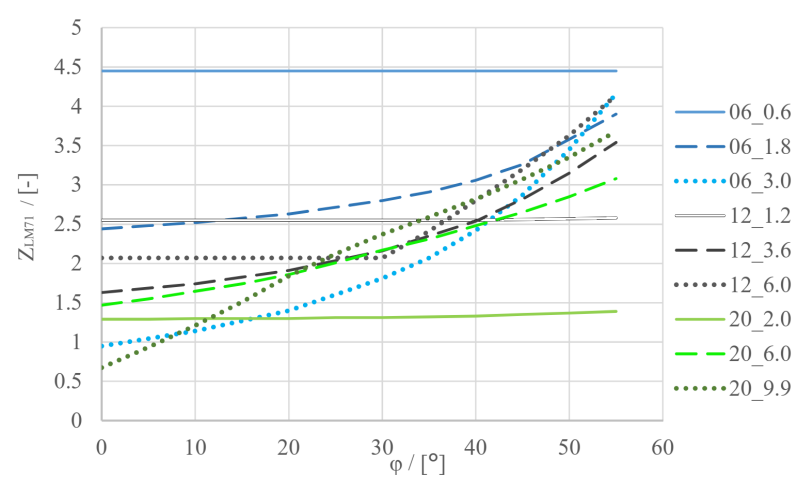

Figure 19. Load carrying capacity in dependence on angle of internal friction of soil.

LCC significantly. It is caused by a passive earth pressure, which stabilizes the vault in the horizontal direction in ULS very well. Note that for arches with low sagitta, the increase of the LCC is very small, because the mode of failure is governed by the crush of the masonry, according to Fig. 1 .

\subsection{Cohesion of THE SOIL}

As it can be seen from the Figure 20, the increase of soil cohesion brings the final LCC slightly higher. The cohesion helps to increase the passive earth pressure, see equation 6 and stabilizes the vault. Because of the value of $m_{p c}$, which is equal 0.05 , the increase of the LCC is very low.

\subsection{EFFECTIVE WIDTH}

For an analysis in 2D and specific cases of 3D analysis, the program LimitState:RING uses an effective width concept. This method is used, because the shear and tensile strength between the blocks of masonry in the transverse direction is unknown and probably very small, so a detailed modelling is usually not possible.

The effective vault width used in the calculation depends on the load distribution angle and the depth over which the load can spread. The dependence of the LCC on the effective width is linear. 


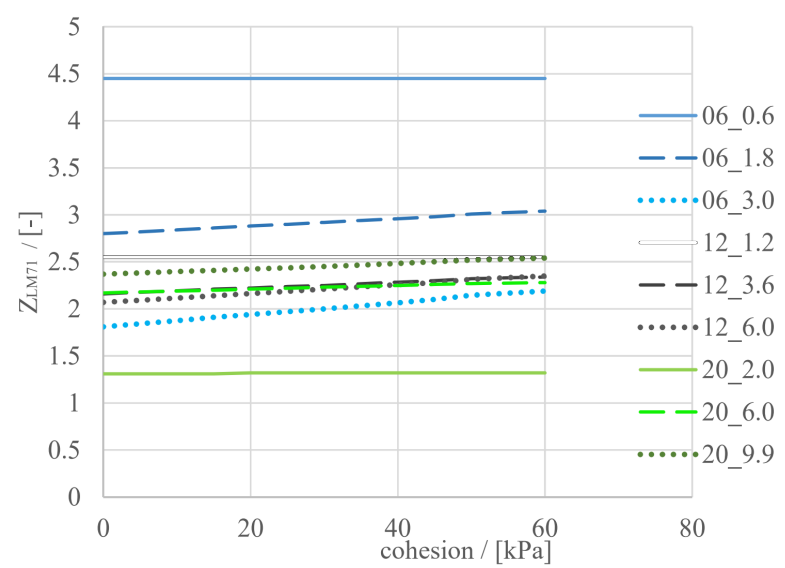

FIGURE 20. Load carrying capacity in dependence on cohesion of soil.

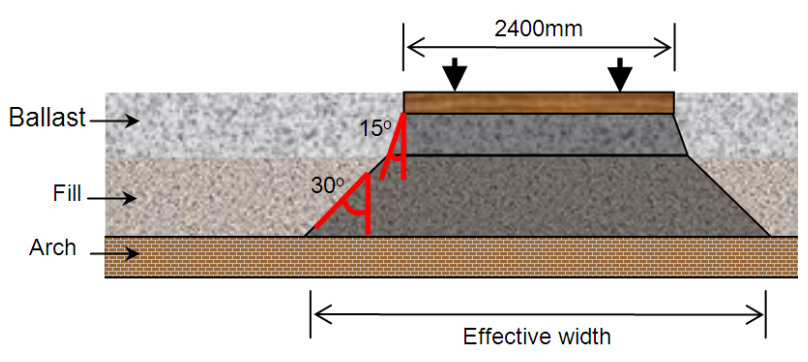

FiguRe 21. Assessment of effective width used in program LimitState:RING.

\subsection{Poisson RATIO}

Poisson ratio doesn't impact the normal and shear stresses in the longitudinal direction of the vault, which are verified. The transverse direction of the vault is not verified. The standard [4 doesn't demand it.

\subsection{Shape OF THE VAUlT}

All common or uniquely occurring shapes (according to [17]) of the vault were analysed, see the shapes in the Figure 22,

Parameters marked with * are considered fixed in this study. A vault with an internal diameter of 5 $\mathrm{m}$ and depth of the backfill at the top of $0.25 \mathrm{~m}$ and a ballast of $0.5 \mathrm{~m}$ was considered. Four different vault heights in the middle of the span (= sagitta) of 2.5, 1.75, 1 and $0.5 \mathrm{~m}$ were compared. In building structures, there are special vaults, which are not considered in this article, e.g. arches composed of several circles and ellipses, rising arch (one support is higher than the second one) or arch of Islamic architecture. The Figure 23 shows the assessed shapes of intrados of the vault, the extrados is shown only for the circular arch for clarity.

The resulting safety factors for different shapes of vaults can be seen in the Figure 23

The results are influenced by the fact that all possible failure modes can happen, which means that especially for ellipse - the LCC is decreased signifi-

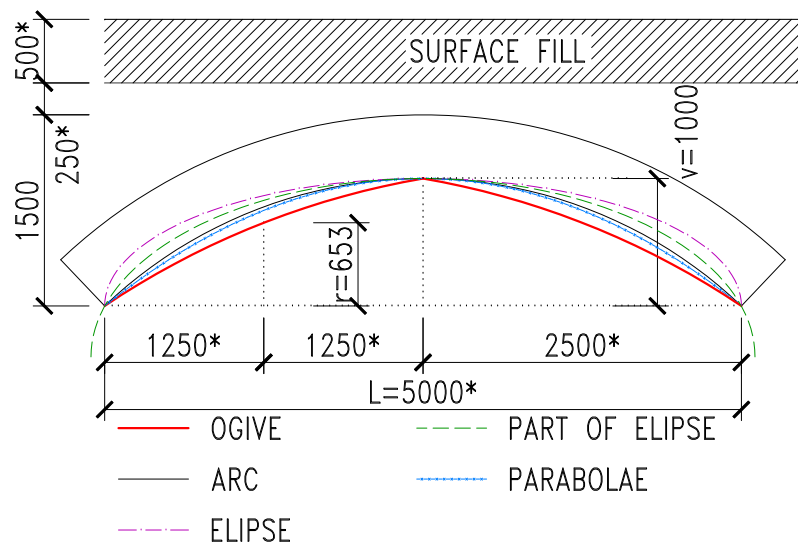

Figure 22. Considered shapes of vaults.

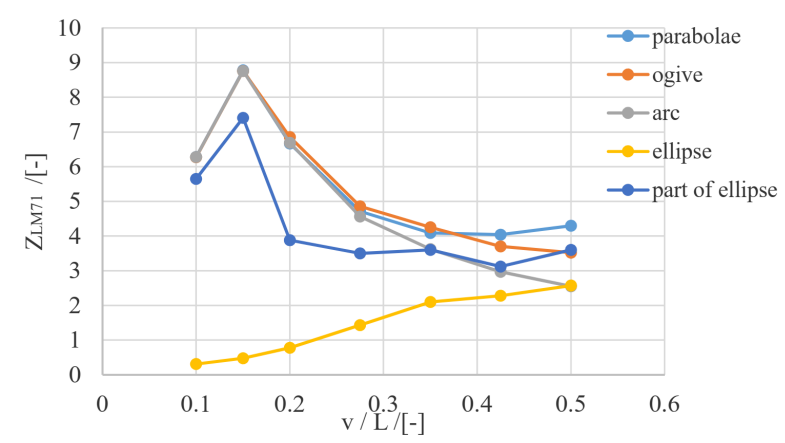

Figure 23. Load carrying capacity in dependence on ratio $v / L$

cantly by shear force. Depending on the chosen part of the ellipse, the resulting LCC of the ellipsoid bridge is between the two curves in the plot. Curve "ellipse" represents one half of the ellipse. For the ogive (Gothic) shape, only the maximal LCC is plotted. See detailed results of an ogive-shaped vault in the Figure 24 (name of set " 0.5 " means vault $v / L=0.5$ ). The changing parameter is $r$, see the Figure 22.

The highlighted value (always the second set from the two sets with the same name) represents the value of $r$ such that the shape of the arch is circular. For the low ratio $v / L$, the circular shape has the highest LCC, for the high values of ratio $v / L$, the Gothic shape has a higher LCC than the circular shape.

\subsection{THICKNESS OF THE VAULT}

Thickness of the masonry blocks of vault is a very sensitive parameter. Increasing the thickness leads to increasing the area, where thrust line can develop. It also increases the compressed area, the stresses from the load decrease rapidly. See the results of the modelling in Figure 25

\section{Discussion}

The comparison of the investigated parameters is carried out in two ways: 


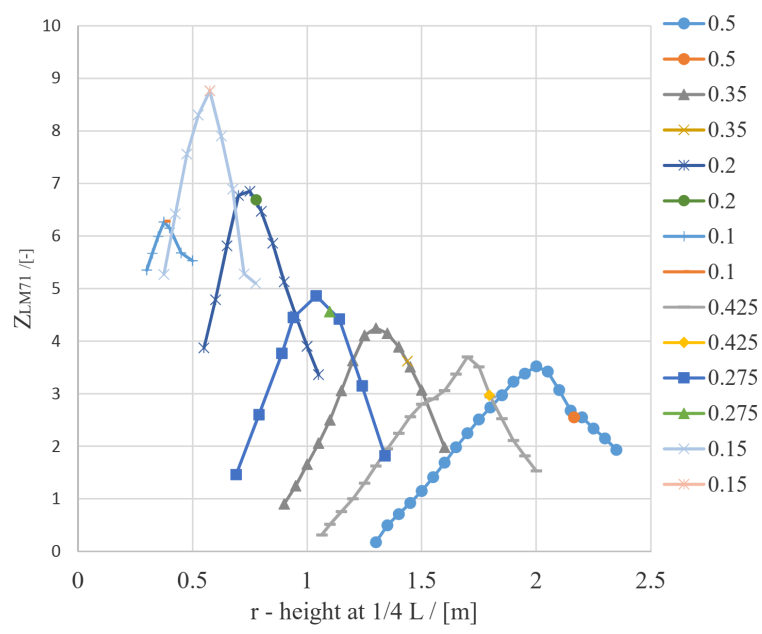

Figure 24. Dependence of LCC on $r$ (see Figure 22,

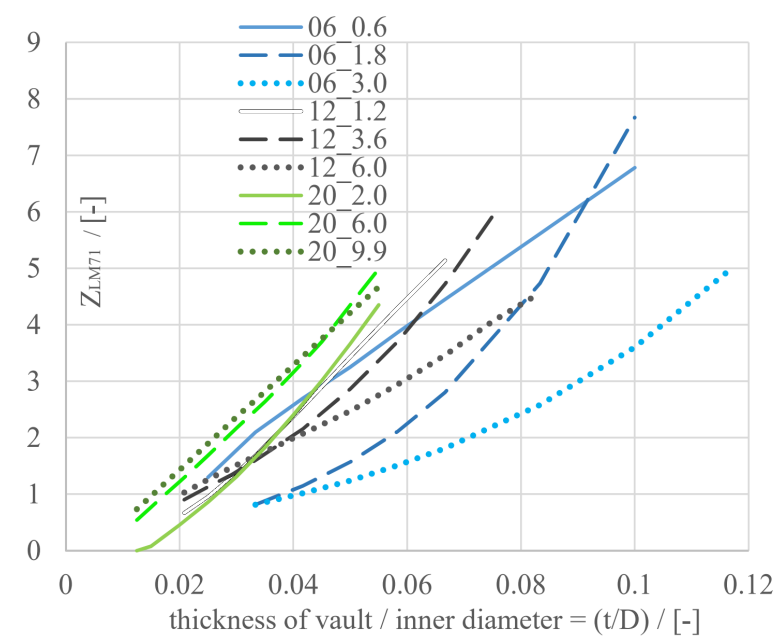

Figure 25. Dependence of LCC on ratio $t / D$.

- In the Figure 26, the total differences of $Z_{L M 71}$ within the investigated scope of parameters are compared.

- In the Figure 27, the average "normalized" derivatives of resulting functions are compared. "Normalized" derivative is used because of the differences between the scope of the investigated parameters. For example, the angle of internal friction varies from $0-55^{\circ}$ and the ratio $t / D$ varies from 0.008 to 0.1166 . Derivatives are incomparable due to this fact. "Normalized" derivative means that, for all functions, the scope of the investigated parameter is set to 1 .

For both cases, average of all investigated bridges is displayed.

\section{Conclusions}

Sensitive parameters identified by this study are the ones, which should be investigated precisely by the diagnostic survey. The medium-sensitive parameters are good to know, but few tests are usually enough.

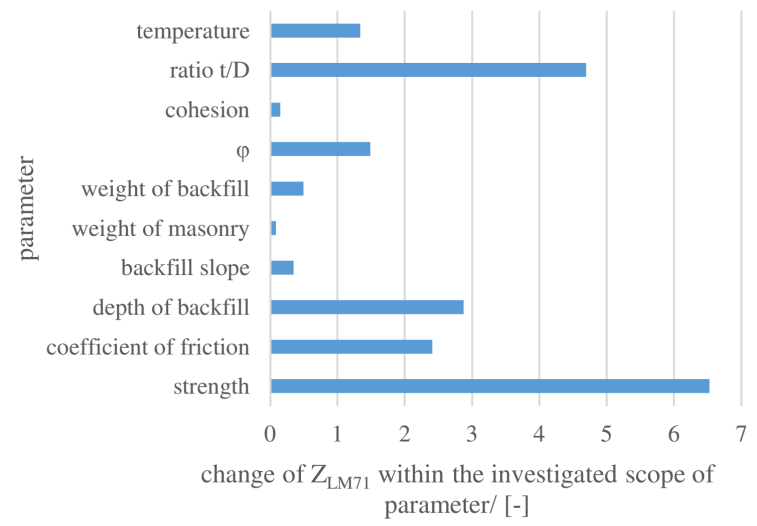

Figure 26. Comparison of investigated parameters total differences between final $Z_{L M 71}$.

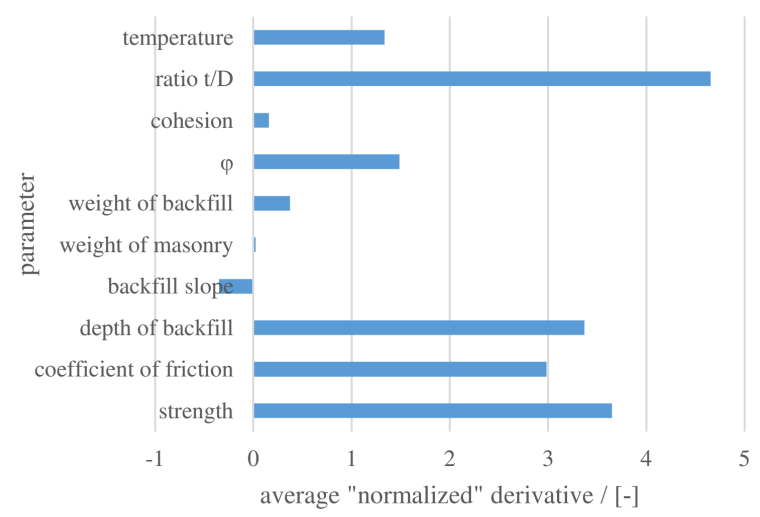

Figure 27. Comparison of investigated parameters "normalized" derivatives.

The most sensitive parameters are the masonry strength and thickness of the vault. Masonry strength is important especially for vaults of low sagitta, for which the crushing of masonry is usually the decisive failure mode.

The coefficient of friction between blocks is not important for circular vaults, but other shapes, especially ellipse and ogive, are very sensitive to the coefficient of friction. The Eurocode significantly underestimates the value of the coefficient of friction, especially the LCC of elliptic shape vaults would be very low according to the Eurocode.

Modulus of elasticity, considered change of temperature and coefficient of thermal expansion are three parameters, which influence on final stresses in the structure the most. Final resulting stresses caused by the temperature load might be so high as to cause a collapse of the vault due to crushing of the masonry for the low strength of the masonry or due to the maximal eccentricity of the load. Parameters for the calculation are, therefore, also very sensitive.

The depth of the backfill, soil angle of internal friction, effective width of the vault and shape of the vault are medium-sensitive parameters. The longitudinal slope of the railway, specific weight of the masonry, 
specific weight of the backfill, Poisson number and cohesion of the backfill are parameters, which have a low impact on the final LCC.

\section{ACKNOWLEDGEMENTS}

I would like to express special thanks to company Pontex s.r.o. for the diagnostic survey 9 .

\section{REFERENCES}

[1] B. Stecinsky. Wall arches of railway bridges. Roads and Railways (5), 2012.

[2] D. Proske, P. Gelder. Safety of Historical Stone Arch Bridges. Springer, 2009. DOI:10.1007/978-3-540-77618-5.

[3] M. Somr. Numerical Simulation of Cocciopesto-based Masonry Structures. Master thesis, 2011.

[4] D. Pume, K. Lorenz. En 1996-1-1 - design of masonry structures. Standard, ÚNMZ, 2007.

[5] En 1991-2 - traffic loads on bridges. Standard, ÚNMZ, 2005.

[6] SŽDC. Systematic directive for determination of load carrying capacity of bridges, 2015.

[7] Limitstate:ring manual, 2016. http://www.limitstate.com/files/pdf/ring/RING_ User_Manual.pdf.

[8] Midas user manual, 2019. https://en.midasuser.com/training/main.asp

[9] K. Institute, Pontex, Inset. Diagnostics of legion bridge, 2019.
[10] M. Sadd. Elasticity. Theory, Applications and Numerics. Elsevier Butterworth-Heinemann, 2005. DOI:10.1002/200590048

[11] R. McMeeking, J. Rice. Finite-element formulations for problems of large elastic-plastic deformation. International Journal of Solids and Structures 11(5):601616, 1975. DOI:10.1016/0020-7683(75)90033-5.

[12] M. Drahorád. Load-bearing capacity of masonry arch bridges. In International Conference Engineering Mechanics, vol. 19, chap. 23, pp. 33-34. Institute of Thermomechanics of the Czech Academy of Sciences, v. v. i., 2013.

[13] M. Vokál, M. Drahorád. The load bearing capacity of railway masonry arch bridges. Transactions of the V̆̌SB - Technical University of Ostrava, Civil Engineering Series 18(2), 2019. DOI:10.31490/tces-2018-0019.

[14] J. Klouda. En 772-1 - methods of test for masonry units, part 1: Determination of compressive strength. Standard, ÚNMZ, 2016.

[15] R. Olivito, M. Esposito, N. Totaro. Experimental investigation for the friction evaluation in the masonry structures. International Journal of Masonry Research and Innovation 1(1):27-47, 2016. DOI:10.1504/ijmri.2016.074729.

[16] I. U. of Railways. Irs 70778-3 - recommendations for the inspection, assessment and maintenance of masonry arch bridges, 2017.

[17] E. Lipanská. Historic vaults. El Consult, 1998. 